\title{
Anti-sticking Re-Ir coating for glass molding process
}

\author{
Xiao-yan Zhu ${ }^{\text {a }}$, Jun-jun Wei ${ }^{\text {a,* }}$, Liang-xian Chen ${ }^{\text {a }}$, Jin-long Liu ${ }^{\text {a }}$, Li-fu Hei ${ }^{\text {a }}$, Cheng-ming Li ${ }^{\text {a }}$, Yong Zhang ${ }^{\text {b }}$ \\ ${ }^{a}$ Institute for Advanced Materials and Technology School of Materials Science and Engineering, University of Science and Technology Beijing, Beijing 100083, P.R. China \\ ${ }^{\mathrm{b}}$ Institute of Mechanics, Chinese Academy of Science, Beijing 100190, P.R. China
}

\section{A R T I C L E I N F O}

Available online 9 January 2015

\section{Keywords:}

Anti-Sticking Property

Monolayers

Rhenium

Iridium

Multilayers

Thin Films

Interfaces Resistance

\begin{abstract}
A B S T R A C T
The sticking of glass to the dies is a critical problem in glass molding process which limits the quality of products and lifespan of mold. Three kinds of protective coatings, including monolayer Re, Ir and Re/Ir multilayer were designed to mitigate the sticking and to improve the lifespan of mold. The interaction between barium crown optical glass and WC/Co mold materials (Co-10 at. \%) with these three protective coatings was investigated. The results demonstrated that anti-sticking performance of multilayer coating is better than that of monolayer Re, Ir coating. The addition of interfaces resistance in multilayer is the main reason for improvement of antisticking ability of multilayer Re/Ir film. It was also verified that the Re/Ir multilayer coating possesses the highest nanohardness (24.5 GPa), as well as the largest wetting angle $\left(168.1^{\circ}\right)$.
\end{abstract}

(c) 2015 Elsevier B.V. All rights reserved.

\section{Introduction}

Due to increasing market demand for glass components with high precise and reduced size, the glass lenses are required to be more diversified in sizes and shapes, better form accuracy/surface roughness, as well as more competitive in price. Conventional glass grinding and polishing techniques have advantage in producing spherical glass lenses. However, it costs considerable money and time to produce complex optical components such as micro lenses and aspheric lenses.

The introduction of glass molding process (GMP) to the precision optics industry has made it possible to manufacture high precision aspherical optical components at a high volume [1-5]. During glass molding process, the mold surface directly contacts with glass at an elevated temperature higher than glass transition temperature ( $\mathrm{Tg}$ ) [6]. Simultaneously, it also suffers from mechanical and thermal cyclic loads. Thus the chemical reaction easily occurs at the contact area between glass and mold, which leads to a premature mold failure.

Only particular materials such as tungsten carbide and silicon carbide can withstand such a harsh environment and meet the hardness requirement involved in GMP. However, without a protective coating, those materials are also not suitable for the application of GMP due to the interfacial reactions. In order to reduce the interfacial reactions, various coatings have been employed to protect mold, such as hard carbon thin films [7-13] and precious metal alloy films [8,14-16], including platinum-iridium (Pt-Ir), rhenium-iridium (Re-Ir) and so on. Previous studies [15] pointed out that a specially developed design for particular glasses was the most effective way to optimize the performance of

\footnotetext{
* Corresponding author. Tel./fax: + 861062332475.

E-mail addresses: 1988zhuxiaoyan2008@163.com (X. Zhu), weijj@ustb.edu.cn (J. Wei).
}

protective coating. Commercial dense barium crown optical glass has been widely used as aspherical glass lens in China. In this study, different protective coatings based on $\mathrm{Re} / \mathrm{Ir}$ were prepared and the interfacial reactions for all kinds of coatings were compared and analyzed using high temperature wetting tests, in which the coatings directly contacts dense barium crown optical glass. Based on the results, a preferable coating design for mold of dense barium crown optical glass was proposed.

\section{Experimental details}

Re/Ir coating was deposited onto tungsten carbide (WC) substrate using RF magnetron sputtering technique. Cemented tungsten carbide substrates (WC-10 wt. \% Co) with dimensions of $\Phi 15 \times 3 \mathrm{~mm}^{3}$ were grounded and polished using $0.5 \mu \mathrm{m}$ diamond paste. They were subsequently cleaned by the ion sources of $1250 \mathrm{~V}$ for $15 \mathrm{~min}$ to improve the adhesion with the substrate. Three types of protective coatings, monolayer Re, monolayer Ir and multilayer Re/Ir were generated. The substrate holder was heated to $300{ }^{\circ} \mathrm{C}$. Ar flow rate was controlled at $30 \mathrm{sccm}$ and the working pressure was $3.2 \times 10^{-1} \mathrm{~Pa}$. Before protective

Table 1

The major constituents and $\mathrm{Tg}$ temperature of optical glass.

\begin{tabular}{lllllll}
\hline Glass & Diameter $/ \mathrm{mm}$ & $\mathrm{Tg} /{ }^{\circ} \mathrm{C}$ & $\mathrm{Ts} /{ }^{\circ} \mathrm{C}$ & nd & vd & Composition \\
\hline D-ZK3 & 7.6 & 511 & 546 & 1.58913 & 61.15 & $\mathrm{SiO}_{2} 30-40 \%$ \\
& & & & & & $\mathrm{~B}_{2} \mathrm{O}_{3} 20-30 \%$ \\
& & & & & & $\mathrm{CaO}_{0} 0-10 \%$ \\
& & & & & & $\mathrm{Al}_{2} \mathrm{O}_{3} 0-10 \%$ \\
& & & & & & $\mathrm{BaO}_{10} 10-20 \%$ \\
& & & & & & $\mathrm{Sb}_{2} \mathrm{O}_{3} 0-10 \%$
\end{tabular}





Fig. 1. SEM image of the cross-section of the monolayer (a) Re and (b) Ir protective coating.

coating deposition, a Ta interlayer with a thickness of $80 \mathrm{~nm}$ was deposited with a fixed input power of $120 \mathrm{~W}$. The Re and Ir protective coatings were deposited with a fixed input power of $120 \mathrm{~W}$ and $100 \mathrm{~W}$, respectively. Multilayer Re/Ir coating of 40 layers were achieved by alternative

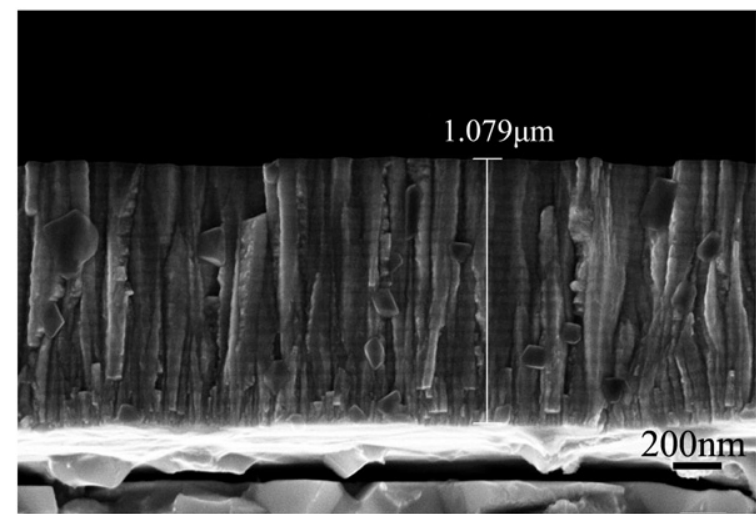

Fig. 3. SEM image of the cross-section of Re/Ir multilayer coating.

deposition. The anti-sticking capacity of monolayer and multilayer coatings was studied employing the sessile-drop technique (Wetting test, DATAPHYSICS, Germany). The surface morphology of coatings were observed using field emission scanning electron microscope (FESEM, ZEISS SUPRA 55, Japan). Energy Dispersive Spectrometer (EDS, JSM6510LA) attached to the scanning electron microscopy (SEM, JSM6510A, JEOL, Japan) was employed to detect the elements diffused into its counterpart during the experiment. The electron accelerating voltage is $10 \mathrm{kV}$. The surface nanohardness was measured using a nano-indentation tester (Nano Indenter XP). The surface roughness and peak-valley were investigated using DEKTAK 150 (U.S.A). Each experiment was repeated five times for more accurate results with a standard deviation.

During the high temperature wetting test, the D-ZK3 optical glass balls, which are dense barium crown optical glass manufactured by CDGM GLASS Co., LTD, P. R. China, were placed onto the WC/Co substrate in an environment of vacuum. The pressure was controlled at $10^{-3} \mathrm{~Pa}$ while the temperature was around $631^{\circ} \mathrm{C}\left(120^{\circ} \mathrm{C}\right.$ above $\mathrm{Tg}$ of optical glass, $511^{\circ} \mathrm{C}$ ) for $30 \mathrm{~min}$. Then the contract angle of optical
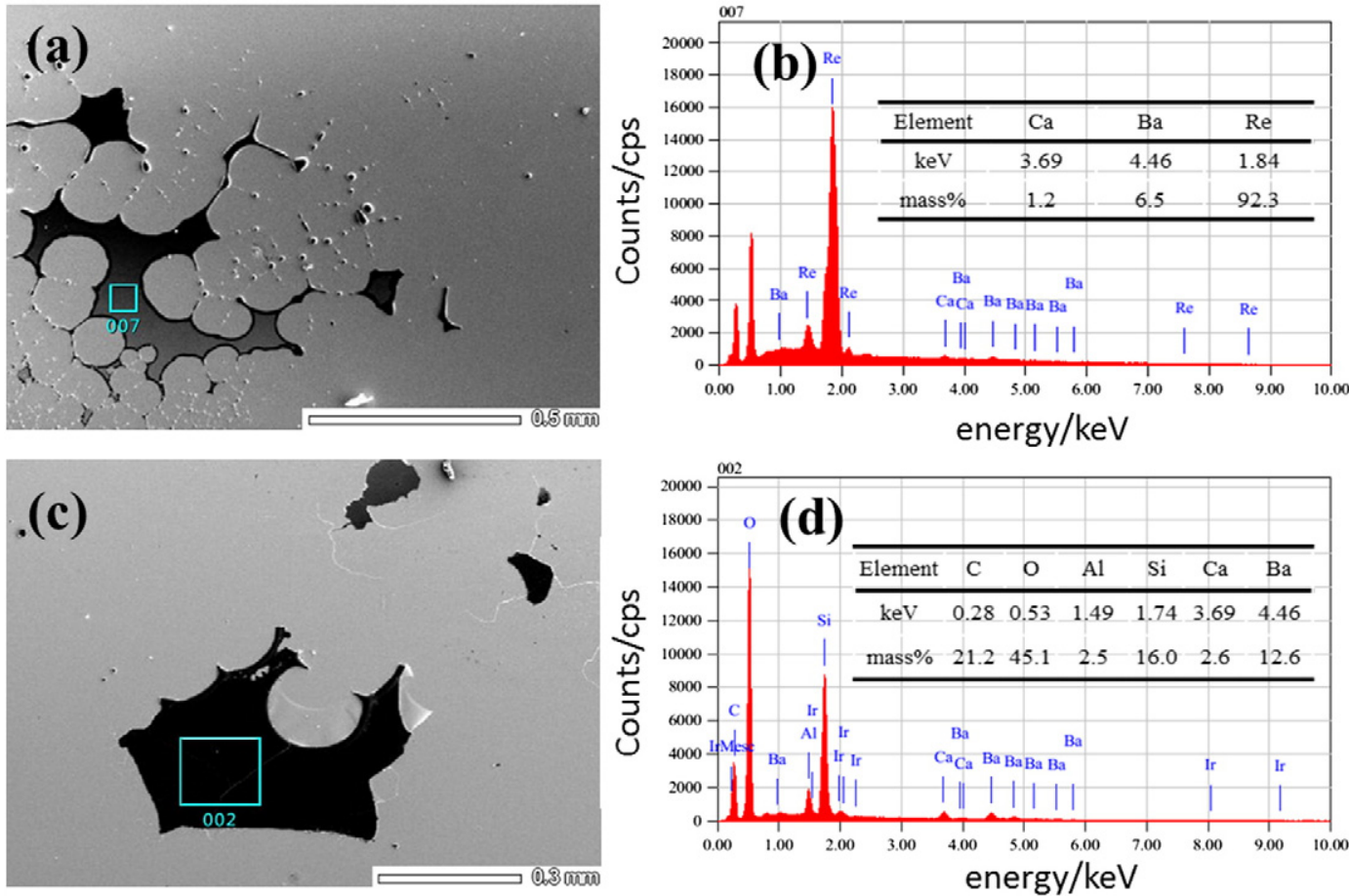


tests. 
Table 2

Surface quality and mechanical properties of Re, Ir monolayer and Re/Ir multilayer coatings.

\begin{tabular}{|c|c|c|c|c|}
\hline \multirow{2}{*}{$\begin{array}{l}\text { Protective } \\
\text { coatings }\end{array}$} & \multicolumn{2}{|c|}{ Surface accuracy } & \multicolumn{2}{|c|}{ Mechanical properties } \\
\hline & $\mathrm{Ra} / \mathrm{nm}$ & $\mathrm{PV} / \mathrm{nm}$ & $\begin{array}{l}\text { Young's } \\
\text { Modulus/GPa }\end{array}$ & Hardness/GPa \\
\hline Monolayer Re & $3.5 \pm 0.7$ & $42.9 \pm 29.9$ & $338.2 \pm 36.1$ & $11.7 \pm 1.4$ \\
\hline Monolayer Ir & $4.1 \pm 0.4$ & $35.9 \pm 11.6$ & $304.5 \pm 37.1$ & $12.9 \pm 1.5$ \\
\hline Multilayer ReiIr & $2.9 \pm 0.6$ & $20.8 \pm 25.8$ & $627.0 \pm 21.3$ & $24.5 \pm 1.2$ \\
\hline
\end{tabular}

glass on coating was measured. The major constituents and Tg of optical glass are listed in Table 1 . The constituents of glass can be basically divided into three categories namely network formers, network
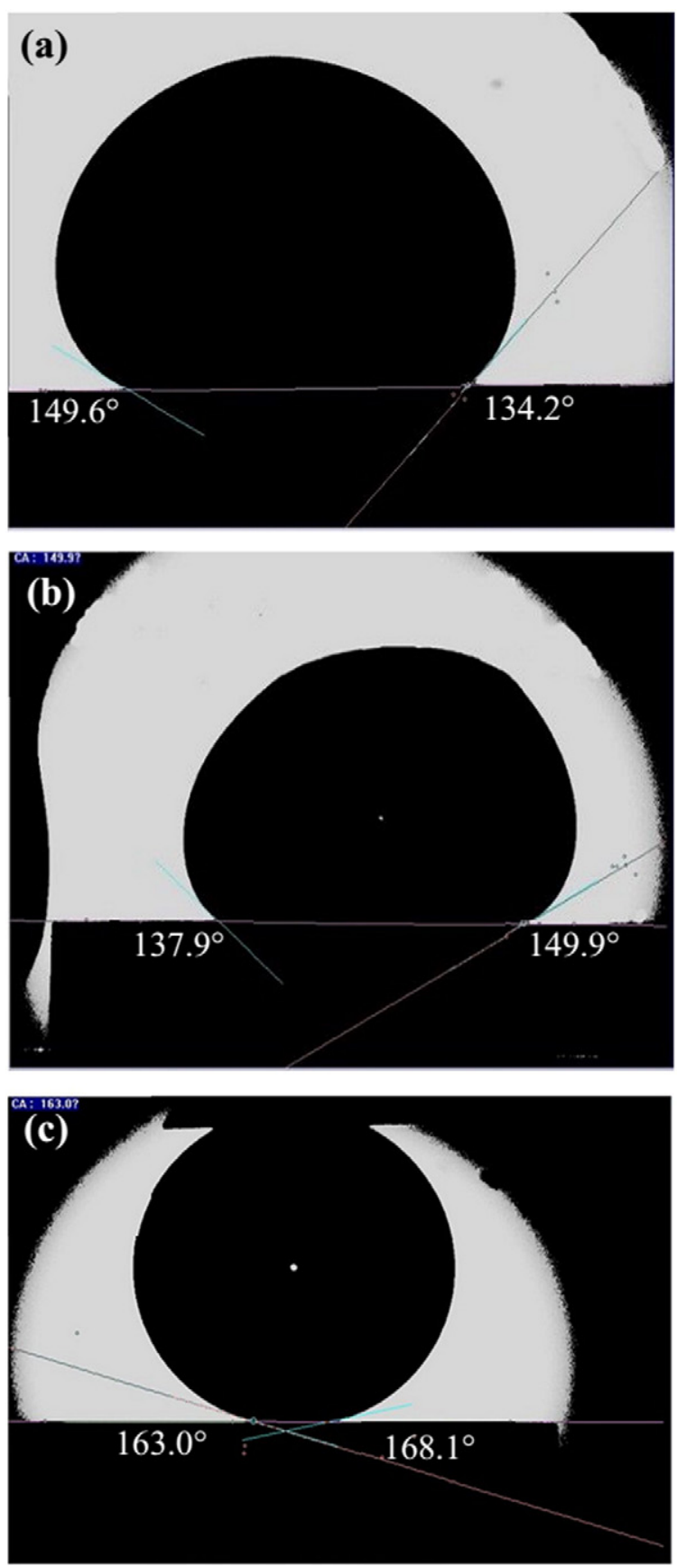

Fig. 4. High temperature wetting angle of optical glass in liquid state on different protective coatings surfaces (a) monolayer Re, (b) monolayer Ir, (c) multilayer Re/Ir. modifiers, and intermediates. Network formers (e.g. $\mathrm{SiO}_{2}, \mathrm{~B}_{2} \mathrm{O}_{3}$, etc.) are the main structure of the glass. Network modifiers (e.g. $\mathrm{K}_{2} \mathrm{O}$, $\mathrm{Na}_{2} \mathrm{O}, \mathrm{CaO}, \mathrm{BaO}$, etc.) including mostly the oxides of IA, IIA elements play a role of breaking up the network and intermediates. The intermediates (e.g. $\mathrm{Zn}, \mathrm{F}_{2} \mathrm{Al}_{2} \mathrm{O}_{3}$, etc.) act as network formers or network modifiers. In order to make it easy to mold the optical glass at a low temperature, the molding glasses normally have a high proportion of network modifiers.

\section{Results and discussion}

Fig. 1 shows the SEM image of the cross-section of the monolayer (a) Re and (b) Ir protective coating. The microstructure of monolayer Re and Ir protective coating exhibits a typical columnar structure. The thickness of protective coating is $400 \mathrm{~nm}$. The interlayer Ta with a thickness of $80 \mathrm{~nm}$ not only acts as a diffusion barrier, but also plays an important role in enhancing adhesion between protective film and substrate.

Fig. 2 shows the SEM images and EDS analysis of residual reactant around contact area after wetting test of single Re, Ir films. Ca, Ba elements of glass were detected at the contact area of Re film (Fig. 2a and b), which indicated that network modifiers elements were easier to diffuse into the coatings [15]. It is because that the dissociation energy of $\mathrm{CaO}$ and $\mathrm{BaO}$ are 257 and $260 \mathrm{kcal} / \mathrm{g}$-atom, respectively, which are lower than that of Si (424 kcal/g-atom) and B (356 kcal/g-atom). Thus $\mathrm{CaO}$ and $\mathrm{BaO}$ are easier to be decomposed [17]. Subsequently, the escaped $\mathrm{Ca}$ and $\mathrm{Ba}$ elements condensed on the surface of the coating and formed $\mathrm{CaO}$ and $\mathrm{BaO}$. The presence of black scraps and $\mathrm{Si}$ at the contact area of Ir film indicated the adhesion of glass on Ir film (Fig. 2c and d). The melding of glass and coating may be attributed to mechanical locking caused by the tensile stress existed in the Ir film.

To improve the anti-sticking performance of the protective coating, the Re/Ir multilayer film was designed. Fig. 3 illustrates the microstructure of multilayer film which exhibits the coexistence of a columnar and nano-laminated structure. The Re/Ir multilayer coating contains twenty bilayers of Re/Ir. The thickness of each Re/Ir bilayer is nearly $50 \mathrm{~nm}$.

The roughness and peak-valley value of different protective coatings are listed in Table 2. The nanohardness of Re/Ir multilayer film is much higher than that of monolayer Re, Ir, which can be explained by the HallPetch reinforcement theory [18]. All of the deposited films show a roughness ( $\mathrm{Ra}$ ) less than $5 \mathrm{~nm}$ and $\mathrm{P}-\mathrm{V}$ less than $150 \mathrm{~nm}$, which meets the requirement of precision mold surface accuracy.

It is well known that high temperature induces inter-diffusion between coating and glass. The severer the reaction is, the smaller the wetting angle is [10]. Fig. 4 shows the wetting angle of optical glass on various protective coatings. Monolayer Re has the smallest wetting angle of $134.2^{\circ}$, while multilayer Re/Ir coating has the largest wetting angle of $168.1^{\circ}$. Previous studies $[19,20]$ showed that ordered nano-

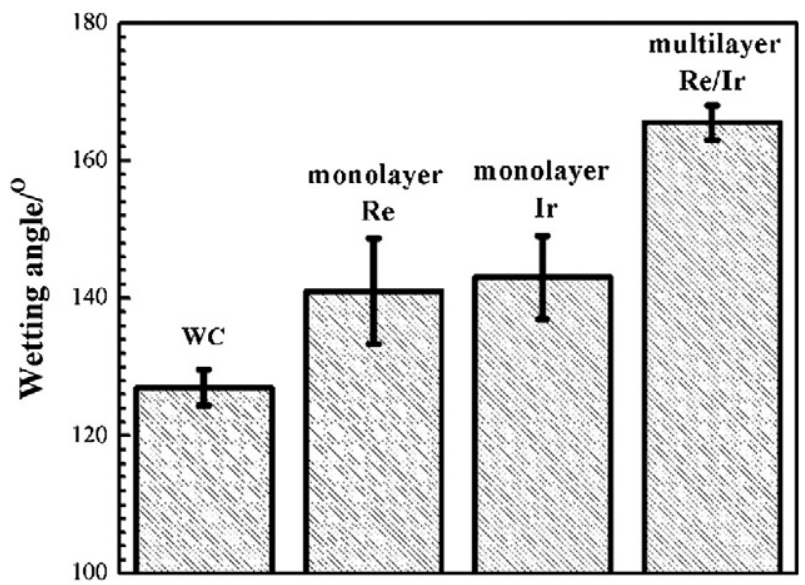

Fig. 5. The wetting angle of optical glass on different protective coatings at $631{ }^{\circ} \mathrm{C}$. 

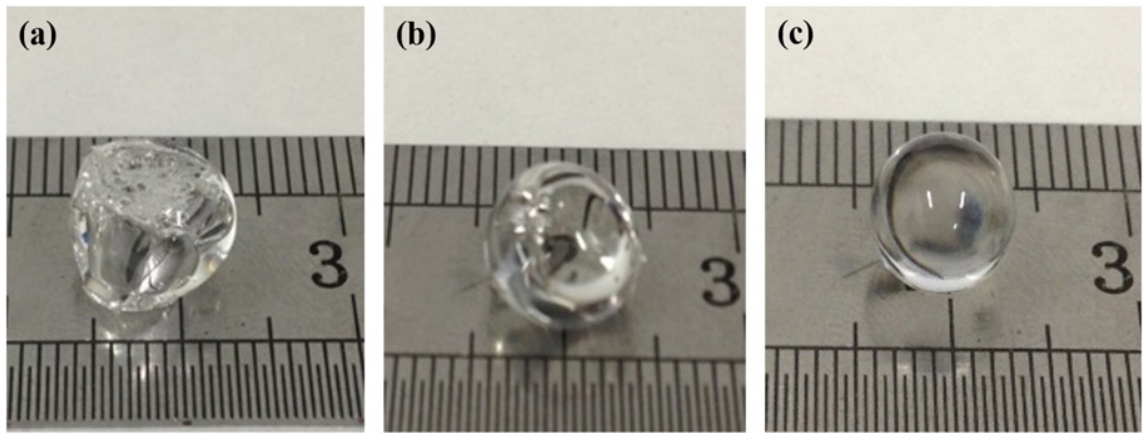

Fig. 6. Surface appearance of optical glass gobs after high temperature wetting tests with different coatings: (a) monolayer Re coating, (b) monolayer Ir coating, (c) multilayer Re/Ir coating.

Table 3

Optical glass state and dimension of contact area after the high temperature test with various coatings.

\begin{tabular}{lll}
\hline Different coatings & $\begin{array}{l}\text { Optical glass state after } \\
\text { wetting test }\end{array}$ & $\begin{array}{l}\text { Dimension of the glass } \\
\text { contact area } / \mathrm{mm}\end{array}$ \\
\hline Monolayer Re & Translucent & 7.2 \\
Monolayer Ir & Transparent & 6.1 \\
Multilayer Re/Ir & Transparent & 1.7 \\
\hline
\end{tabular}

structure enhanced the bonding between Re and Ir at interface, making it difficult for $\mathrm{Ca}$, Ba of glass network modifiers elements to penetrate in protective films, and alleviate adhesion of glass. The diffusion resistance $[21,22]$ of monolayers are mainly caused by grain boundaries. The addition of interfaces increased the diffusion resistance of multilayer, preventing elements of substrate from initiating the interfacial reaction.

The wetting angles of substrates with and without coatings are illustrated in Fig. 5. The wetting angle of WC (10 wt. \% Co) is lower than $130^{\circ}$. Monolayer Re, Ir has a contact angle larger than $140^{\circ}$, whereas multilayer coating exhibits larger wetting angle. This indicates that $\mathrm{Re} / \mathrm{Ir}$ multilayer coating can offer better protection than Re, Ir monolayer films.

The surface appearance of optical glass after high temperature wetting tests was also evaluated (Fig. 6). In general, the glass loses its transparency and turns into translucent as the reaction progresses [8]. The glass on monolayer Re coating is translucent, while the glasses on monolayer Ir and multilayer Re/Ir coating stay transparent.

The more violent the reaction is, the larger the dimension of the glass contact area is. The dimension of the contact area after the high temperature wetting tests is shown in Table 3. The glass on monolayer Re coating has the largest contact dimension of $7.2 \mathrm{~mm}$. However, the glass on $\mathrm{Re} / \mathrm{Ir}$ coating has the smallest contact dimension of $1.7 \mathrm{~mm}$. The result is consistent with the result of the high temperature wetting test. The SEM image and EDS analysis of residual reactant left on Re/Ir multilayer coatings after high temperature wetting test are shown in Fig. 7.

Compared to the results shown in Fig. 2, anti-sticking performance has been significantly improved for Re/Ir multilayer coating. There are no glass elements left on the contact surface. It means that Re/Ir multilayer coating has better anti-sticking performance than Re, Ir monolayer coating for the optical glass. The Re/Ir multilayer is considered as an improved protective coating for molding the optical glass.

\section{Conclusions}

The anti-sticking ability of monolayer Re, Ir and multilayer Re/Ir with barium crown optical glass was evaluated by high temperature wetting tests at $631{ }^{\circ} \mathrm{C}\left(\mathrm{Tg}+120{ }^{\circ} \mathrm{C}\right)$. Multilayer films exhibited better antisticking ability than monolayer coatings, which is probably due to the addition of interfaces resistance. The Re/Ir multilayer films show a nanohardness of $24.5 \mathrm{GPa}$, which is much higher than those of monolayer Re (11.7 GPa) and Ir (12.9 GPa). Ca and Ba elements with low dissociation energy in network modifiers play an important role in triggering the reaction between protective coatings and glass. Optical glass after wetting test with $\mathrm{Re} / \mathrm{Ir}$ multilayer coating has the smallest contact area of $1.7 \mathrm{~mm}$. The Re/Ir multilayer coating shows the largest wetting angle of $168.1^{\circ}$, which indicates that Re/Ir multilayer coating possesses a better anti-sticking ability. Based on the results, Re/Ir multilayer film is considered as the preferable candidate for the mold of barium crown optical glass.

\section{Acknowledgements}

This work was sponsored by the National Natural Science Foundation of China (NSFC) (No.51272024), and the Ph.D. Programs Foundation of Ministry of Education of China (No.20110006110011). The authors deeply appreciated their financial supports.
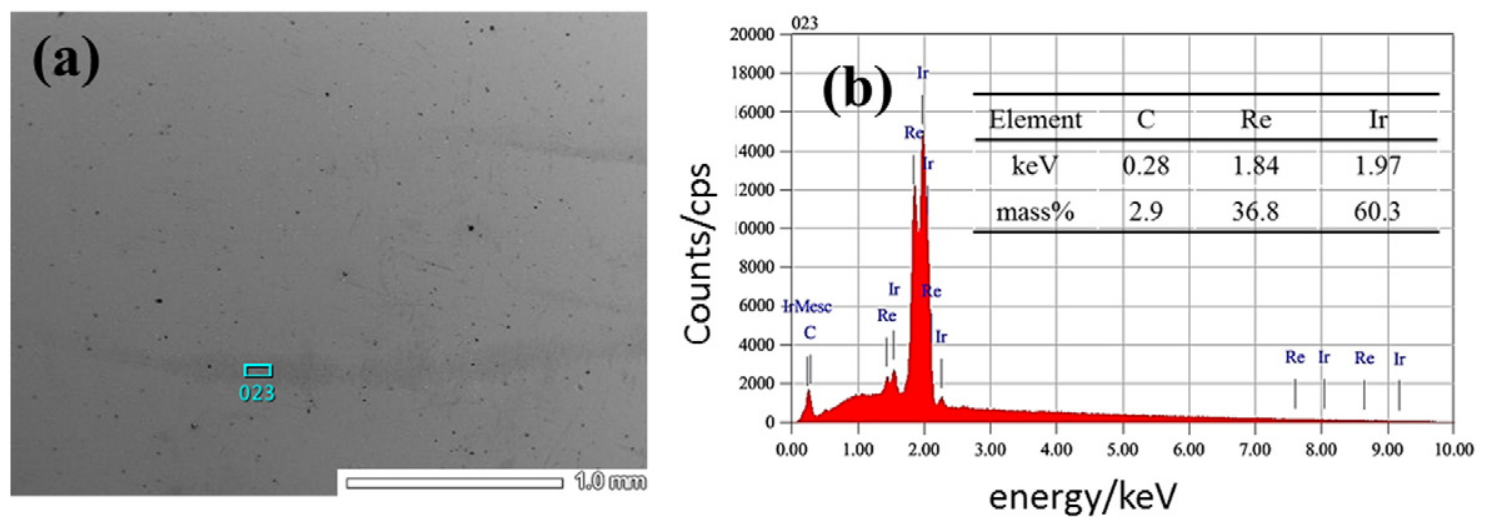

Fig. 7. SEM image (a) and EDS analysis (b) of residual reactant left on Re/Ir multilayer coatings after high temperature wetting test with optical glass. 


\section{References}

[1] R.O. Maschmeyer, R.M. Hujar, L.L. Carpenter, B.W. Nicholson, E.F. Vozenilek, Appl Opt. 22 (16) (1983) 2413.

[2] R.O. Maschmeyer, C.A. Andrysick, T.W. Geyer, H.E. Meissner, C.J. Parker, L.M. Sanford, Appl. Opt. 22 (16) (1983) 2410.

[3] A.Y. Yi, A. Jain, J. Am. Ceram. Soc. 88 (3) (2005) 579.

[4] X. Zhang, J. Non-Cryst. Solids 326 (2003) 519.

[5] M. Katsuki, in: L. Yang, S.M. Wen, Y.L. Chen (Eds.),2nd international Symposium on Advanced Optical Manufacturing and Testing Technologies, Xian, P.R. China., November 1-5, 2005, International Society for Optics and Photonics, 6149, 2006 (61490 M).

[6] M. Aoki, K. Kuribayashi, H. Monji, H. Okinaka, M. Sakai, H. Torii, U.S. Patant No. 4,685,948, Nov. 1987.

[7] K.D. Fischbach, K. Georgiadis, F. Wang, O. Dambon, F. Klocke, Y. Chen, A.Y. Yi, Surf. Coat. Technol. 205 (2) (2010) 312.

[8] C.L. Chao, C.B. Huo, W.C. Chou, T.S. Wu, K.J. Ma, C.H. Kuo, Y.T. Chen, C.W. Chao, Defect and Diffusion Forum, Trans. Technol. Publ. 297 (2010) 808.
[9] H.H. Chien, K.J. Ma, C.H. Kuo, C.B. Huo, C.L. Chao, Y.T. Chen, Defect and Diffusion Forum, Trans. Technol. Publ. 297 (2010) 869.

[10] D. Zhong, E. Mateeva, I. Dahan, J. Moore, G. Mustoe, T. Ohno, J. Disam, S. Thiel, Surf. Coat. Technol. 133 (2000) 8.

[11] J. Brand, R. Gadow, A. Killinger, Surf. Coat. Technol. 180 (2004) 213.

[12] K.J. Ma, H. Chien, W. Chuan, C.L. Chao, K. Hwang, Key Eng. Mater. 364 (2008) 655.

[13] T. Oku, E. Kawakami, M. Uekubo, K. Takahiro, S. Yamaguchi, M. Murakami, Appl. Surf. Sci. 99 (4) (1996) 265.

[14] Y.I. Chen, S.M. Chen, Surf. Coat. Technol. 215 (2013) 209.

[15] C.L. Chao, C.B. Huo, W.C. Chou, Y.R. Lin, K.J. Ma, H.H. Chien, Surf. Coat. Technol. 231 (2013) 567.

[16] S.C. Liu, Y.I. Chen, H.Y. Tsai, K.C. Lin, Y.H. Chen, Surf. Coat. Technol. 237 (2013) 105.

[17] M. Binnewies, E. Milke, Wiley Online Library, 2002.

[18] A. Misra, H. Kung, J. Embury, Scripta Mater. 50 (6) (2004) 707.

[19] Q. Yang, L. Zhao, J. Vac. Sci. Technol. A 21 (3) (2003) 558.

[20] X. Chu, S.A. Barnett, J. Appl. Phys. 77 (9) (1995) 4403.

[21] B.C. Gundrum, D.G. Cahill, R.S. Averback, Phys. Rev. B 72 (24) (2005) 245426

[22] H.K. Lyeo, D.G. Cahill, Phys. Rev. B 73 (14) (2006) 144301. 